DOI: https://doi.org/10.17648/2238-037X-trabedu-v29n1-20219

(c) (1) https://creativecommons.org/licenses/by/4.0/

\title{
EMBATES E PERSPECTIVAS DO TRABALHO PEDAGÓGICO COM DESENVOLVIMENTO DE PRÁTICAS DOCENTES ${ }^{1}$
}

\author{
Conflict and perspectives of pedagogical work with development of teaching \\ practices \\ ALTHAUS, Dalvane ${ }^{2}$
}

\section{RESUMO}

Este artigo traz alguns resultados de uma tese, que parte da experiência de uma pedagoga no Ensino Superior envolvendo a Clínica da Atividade (CA). A CA é uma abordagem teórica-metodológica que visa provocar transformações em situações de trabalho, tendo o professor como protagonista de sua prática e o pedagogo como organizador do processo. Contudo, para atuar em CA é preciso passar por uma formação adequada, que será discutida neste trabalho. Além disso, neste texto, o leitor encontrará uma amostra de intervenção com CA e breves análises dos resultados para o professor e para o interveniente. Considera-se que é uma prática respeitosa para com o profissional docente, e transformadora da prática do profissional da pedagogia.

Palavras-chaves: Trabalho pedagógico. Docência. Clínica da Atividade.

\section{ABstract}

This text brings some results of a thesis, which starts from the experience of a pedagogue in Higher Education involving the Clinic of Activity (CA). The CA is a theoretical-methodological approach that aims to bring about changes in work situations, with the teacher as the protagonist of their practice and the pedagogue as the organizer of the process. However, to act in AC it is necessary to go through a proper training, which will be discussed in this work. In addition, in this text, the reader will find a sample of intervention with $\mathrm{AC}$ and brief analysis of the results for the teacher and the intervener. It is considered to be a respectable practice for the professional teacher, and transforming the practice of the pedagogical professional.

Keywords: Pedagogical work. Teaching. Clinic of Activity.

\footnotetext{
${ }^{1} \mathrm{O}$ artigo parte de alguns resultados de uma pesquisa de doutorado, realizada na Faculdade de Educação da Universidade Estadual de Campinas (FE/Unicamp), sob a orientação da professora Dra Luci Banks-Leite, no período de 2015 a 2019. Contou com apoio da Coordenação de Aperfeiçoamento de Pessoal de Nível Superior - Brasil (CAPES) - Código de Financiamento 001, por meio do Acordo CAPES/FA 13/2014. Analisou material pré-existente no banco de dados do Grupo de Pesquisa Linguagem, Atividade e Desenvolvimento Humano (LAD'Humano), por isso não houve a necessidade de passar pelo COEP, pois este só avalia projetos antes da coleta de dados. Contudo, o GP seguiu todos os procedimentos éticos necessários.

2 Doutora em Educação pela Unicamp. Pedagoga do Departamento de Educação da UTFPR, Campus Pato Branco. E-mail: dalvanea@gmail.com.
} 


\section{INTRODUÇÃO}

Este texto visa a apresentar alguns resultados de um trabalho pedagógico, com desenvolvimento de práticas docentes no Ensino Superior. Mais especificamente, sobre uma atuação junto aos professores de uma Universidade Federal por meio da Clínica da Atividade (CA), com o dispositivo de autoconfrontação, que resultou em um estudo de doutorado.

A docência no Ensino Superior tem despertado preocupação no âmbito acadêmico, uma vez que nem sempre há uma formação inicial para essa finalidade (GATTI, 2004; PIMENTA; ANASTASIOU, 2010; LIMA A; ALTHAUS, 2016; ALTHAUS, 2019). No momento atual, encontra-se preconizado na LDB (1994) que a preparação para o exercício do magistério superior cabe à Pós-graduação Stricto Sensu, contudo, a tradição dessa modalidade é formar pesquisadores e não professores. Desse modo, existe uma lacuna que vem sendo tratada com formação contínua em serviço proposta de diferentes modos, em diversas instituições (por ex. LIMA A; ALTHAUS, 2016; LEITE; BERNARDO; MOREIRA, 2017).

Nesse viés, na Universidade Tecnológica Federal do Paraná, Campus Pato Branco (UTFPR-PB) foi criada uma Clínica da Atividade Docente (CAD) a fim de promover o desenvolvimento de práticas docentes (LIMA A, 2016a). A Clínica da Atividade (CA) é uma concepção teórica-metodológica ligada à psicologia do trabalho, que utiliza de métodos indiretos para buscar mudanças nas situações de trabalho a partir de um movimento psicológico-dialógico de auto-observação (CLOT, 2010; ALTHAUS, 2019).

Para tanto, um dos dispositivos clínicos é o de autoconfrontação. Nesse, de modo geral, o agente da atividade em análise é levado a se observar em situação de trabalho e por meio de um diálogo com outros ${ }^{3}$ e consigo mesmo a perceber como atua e como pode introduzir modificações em seu agir (CLOT, 2010). Portanto, a transformação da ação parte do sujeito, não é imposta a ele por alguém de fora do seu agir. Para isso, os procedimentos são conduzidos por um interveniente ${ }^{4}$ embasado nos preceitos teóricosmetodológicos da CA (ALTHAUS, 2019).

Desse modo, a CA se distancia de outras abordagens em que um especialista na atividade docente presta assessoria para dizer aos professores o que eles devem fazer. Essa abordagem, de especialista externo, frequentemente, é rejeitada pelos docentes e limitada no que concerne ao alcance das atividades no meio laboral (ALTHAUS, 2013).

Contudo, a CA é complexa e segue determinadas especificidades teóricasmetodológicas. Assim, requer uma formação adequada. Nesse trabalho, será apresentado um recorte de um estudo de caso sobre a formação e o papel do

\footnotetext{
${ }^{3}$ Esses outros podem ser destinatários diretos, tal como um colega de trabalho e o interveniente, até um diálogo indireto com o coletivo de trabalho mais amplo denominado de sobredestinátario, que serão abordados nos fundamentos teóricos-metodológicos, bem como o subdestinátario que configura um contato social consigo mesmo (CLOT, 2010).

${ }^{4} \mathrm{Na}$ CA francesa, onde esse método tem sua origem, a pessoa que conduz a intervenção é denominada intervenant, que, em português, frequentemente era traduzido por "interventor", termo que evoca um sentido de autoritarismo, o que não corresponde à perspectiva da CA, por isso opta-se por "interveniente" (ALTHAUS, 2019).
} 
interveniente em CA, vinculado à experiência de uma pedagoga a partir de uma ação no Ensino Superior.

Para tanto, o texto está organizado em cinco tópicos. No primeiro, apresenta-se um breve relato das primeiras experiências da pedagoga em questão, nos Colégios Estaduais do Paraná. No segundo, a experiência com o ensino superior, a partir de uma posição de especialista na atividade docente. No terceiro, expõem-se uma nova abordagem pedagógica realizada a partir da CA. No quarto, apresenta-se algumas especificidades da CA. No quinto, uma amostra de intervenção com uma breve análise. E, por fim, algumas considerações.

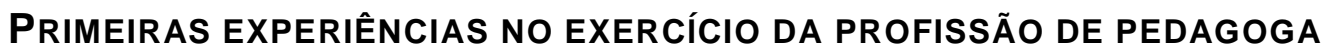

No início da carreira, as primeiras experiências como pedagoga ocorreram em Colégios Estaduais do Paraná, com a Educação Básica, no período de 2006 a 2007. Posteriormente, ingressou-se em concurso público em uma Universidade.

$\mathrm{Na}$ Rede Estadual de Ensino do Paraná, o ingresso ocorreu por meio de concurso ao cargo denominado de "professor pedagogo", com perfil multifunções em: "atividades de coordenação, administração escolar, planejamento, supervisão e orientação educacional" (PARANÁ, 2004). A caracterização do trabalho pedagógico nesse meio pode ser identificada pelas atribuições descritas no edital de concurso 037/2004, que assinalava vinte e sete atribuições para as atividades do cargo; sendo possível notar três linhas de atuação.

A primeira linha, com atividades de gestão escolar, tais como: coordenar a distribuição de aula, a hora-atividade dos professores, o espaço da biblioteca, a aquisição de material didático, o conselho de classe, a elaboração dos documentos pedagógicos, a interação comunidade-escola, etc.

A segunda, com atividades de formação docente continuada para professores, por exemplo: organização de semanas pedagógicas no início de cada semestre letivo, grupos de estudos, reuniões pedagógicas, promoção de momentos de reflexão-ação, etc.

A terceira, com atuação em atividades de orientação educacional, dentre elas: o planejamento de ensino dos professores, o aprimoramento teórico-metodológico, os projetos de recuperação de estudos, além de acompanhar e avaliar o trabalho pedagógico da escola, etc.

Após experienciar a atuação em Colégios Estaduais com amplo rol de tarefas relacionadas a essas linhas, a pedagoga-pesquisadora ingressou, por meio de concurso público, em uma Instituição de Ensino Superior (IES) para atuar junto a formação docente continuada dos professores.

\section{O EXERCícIO DA ATIVIDADE DO PEDAGOGO NO ENSINO SUPERIOR COMO ESPECIALISTA}

A sequência da trajetória da pedagoga ocorreu com o Ensino Superior, em uma Universidade Federal, oriunda do histórico de criação das Escolas de Aprendizes Artífices, em 1909. Incialmente a instituição era voltada aos alunos "desprovidos da fortuna" e passou por várias transformações até se tornar Universidade (LEITE, 2010, p. 
13-14). Atualmente, essa instituição oferece desde cursos técnicos, graduação, até a pós-graduação Stricto Sensu e está configurada com treze Campi.

O Campus, lócus deste trabalho, foi instituído em 1993. Iniciou as atividades com dois cursos técnicos. No ano seguinte, ampliou o quadro de cursos para a graduação (LEITE, 2010, p. 143). E, a partir de 2007 passou a oferecer também cursos de Pós-Graduação Stricto Sensu. Atualmente, encontra-se com aproximadamente trezentos docentes, noventa técnicos administrativos em educação e quatro mil alunos ${ }^{5}$. As áreas de atuação do Campus são treze: 1) Administração; 2) Agrimensura; 3) Agronomia; 4) Ciências Contábeis; 5) Engenharia Civil; 6) Engenharia Elétrica; 7) Física; 8) Humanas; 9) Informática; 10) Letras; 11) Matemática; 12) Engenharia Mecânica; e 13) Química.

Essa Instituição, assim como outras, enfrenta dificuldades nos processos de ensinoaprendizagem, em grande parte pelo fato de que muitos docentes não são preparados para o exercício da docência, embora tenham sido formados pesquisadores e/ou profissionais das áreas de graduação. Diante disso, a gestão do Campus buscou apoio na pedagogia, com abertura de concurso público em que a pedagoga-pesquisadora em questão ingressou.

Ressalta-se que, a experiência que se trazia como pedagoga vinha da prática exercida na educação básica. Porém, diferentemente da Rede Estadual de Educação, onde o pedagogo é incumbido de diversas funções, nessa Universidade a função apontada no termo de posse era de "supervisão" educacional e as atividades solicitadas pela chefia imediata eram de "formação docente continuada", com cursos, palestras e outras atividades que vislumbravam a prática docente (ALTHAUS, 2019).

Especialmente sobre essa função de "supervisão" educacional, embora no momento a atividade pedagógica seja unitária, no final do Séc. XX e início do Séc. XXI se vivenciava perspectivas e tensões em relação às divisões de funções para o trabalho do pedagogo na educação (SANTOS, 2018). Havia uma fragmentação do trabalho como herança da configuração do Curso de Pedagogia por habilitações instituído em ${ }^{1969}{ }^{6}$, sendo a "supervisão escolar" uma das habilitações dentre outras, tais como: orientação educacional, administração escolar, etc. Além disso, a função de "supervisão" educacional era vista de maneira negativa e autoritária (SAVIANI, 2000; RANGEL, 2000; 2008; SILVA JUNIOR, 2000; 2008).

Ao exercer essa função no ensino superior, tinha-se como tarefa principal organizar cursos e palestras para os professores, muitas vezes com especialistas externos, especialmente em momentos de planejamento das atividades de ensino, definidos no calendário da instituição para ocorrerem antes do início de cada semestre letivo (por ex.: FERRI, 2007; NUNES, 2008; WERNEWCK, 2008; FERREIRA, 2009; ANASTASIOU, 2011).

\footnotetext{
${ }^{5}$ Dados disponíveis em: http://portal.utfpr.edu.br/noticias/pato-branco/aniversario-utfpr. Acesso em 19 de abr. 2019.

6 O curso de Pedagogia foi regulamentado pelo Decreto-Lei n. 1.190/1939, que previa a formação de três anos como bacharel e mais um ano para se tornar licenciado. Foi reformulado em 1969 pelo Conselho Federal de Educação através do Parecer №. 252/1969 e da Resolução 02/1969, que previu a formação em licenciatura com habilitações para as diferentes áreas de atuação escolar. Em 2006, foi alterado novamente quando o Conselho Nacional de Educação instituiu Novas Diretrizes Curriculares para o Curso de Pedagogia, com uma formação única para a docência e a gestão educacional (CRUZ, 2011).
} 
No decorrer dos períodos letivos, havia a incumbência de atuar em situações de dificuldades de ensino-aprendizagem. Essas ações, configuravam-se por leituras e discussões visando a reflexão da prática de ensino em pequenos grupos de estudos, e, geralmente, eram conduzidas pela própria pedagoga, embasada em especialistas da área da educação, como, por exemplo: Cunha (1997), Zabalza (2004), Libâneo (2005), Gasparin (2005), Gil (2005) e Pimenta e Anastasiou (2010).

Desse modo, "as ideias, tanto de especialistas externos convidados para palestrarem, quanto o discurso de especialistas que ressoava na atuação pedagógica, com a condução de leituras e cursos, traziam mensagens avaliativas e prescritivas do fazer" (ALTHAUS, 2019, p. 26). Com isso, tais ações focavam na recomendação do que se considera certo e errado na atividade docente, o que remete a ideia equivocada de que alguém pode ser especialista na atividade desenvolvida por outro, por esse motivo eram criticadas e pouca aceitas pelos docentes (ALTHAUS, 2013).

Os especialistas na atividade que o outro realiza, como nos afirma Clot (2007) são "especialistas em "boas práticas"'7, nesse caso, trata-se de "especialistas na atividade do professor" (LIMA A, 2016b). Isto é, são pessoas que falam de uma "atividade idealizada". $E$ "frequentemente apontam o que consideram ser os 'erros' dos professores, indicando em seguida o que os docentes deveriam 'na verdade' fazer para 'acertar"' (LIMA A, $2016 b)$. Essa posição frequentemente é rejeitada pelos docentes, tal como ocorreu no exercício das atividades da pedagoga (ALTHAUS, 2013; 2019).

Com o intuito de se distanciar dessa linhagem, mencionada acima, e de implementar mudanças na atividade, a pedagoga buscou novos rumos e conhecimentos em uma abordagem teórico-metodológica intitulada Clínica da Atividade (CA) (CLOT, 2010; ALTHAUS, 2013; LIMA A, 2016a).

\section{UMA POSSIBILIDADE DE RECRIAÇÃO DA ATIVIDADE DO PEDAGOGO POR MEIO DA CLÍNICA DA ATIVIDADE}

A CA foi criada por Yves Clot (2010) e seus colaboradores, principalmente Daniel Faïta (1997), na França, no final do Séc. XX, ligada à Psicologia do Trabalho e com inspiração na ergonomia francófona e na psicopatologia do trabalho ${ }^{8}$. E, especialmente, com forte ancoragem nas questões psicológicas de Vigotski e seguidores e de estudos da linguagem de Bakhtin e seu círculo (CLOT, 2017).

$\mathrm{Na} \mathrm{CA}$, visa-se a transformação da ação tendo os trabalhadores como protagonistas (CLOT, 2006; 2010). Nessa perspectiva, distancia-se da formação docente continuada tradicional e se toma outros rumos, investe-se no apoio ao desenvolvimento do agir dos professores em suas práticas de ensino. Considera-se o docente como o especialista em sua atividade e, portanto, capaz de mudar sua prática com o apoio de dispositivos metodológicos que privilegiem a "consciência profissional", ou seja, de modo geral, que desenvolvam a capacidade de perceber como realizam seu trabalho e como podem

\footnotetext{
7 Texto original: "les experts en « bonnes pratiques »" (CLOT, 2007, p. 85).

${ }^{8}$ De modo geral, pode-se apontar que, da ergonomia francófona, a CA retém a análise da atividade de cada caso no meio em que as situações de trabalho ocorrem e, especialmente, os conceitos de "trabalho prescrito" e "trabalho realizado", que são abordados no item 4. Da psicopatologia do trabalho, a CA traz a preocupação com a relação dos processos de doença-saúde dos trabalhadores como questão a ser potencializada (CLOT, 2010).
} 
fazer diferente (CLOT, 2010; LIMA A, 2016c; ALTHAUS, 2019). Para tanto, parte-se do meio laboral, a sala de aula, para efetuar ações junto aos docentes que possibilitem a amplificação do seu poder de agir, a partir de suas tomadas de consciência (CLOT, 2010; LIMA A, 2016a).

Com isso, vislumbra-se uma nova maneira de exercer o trabalho pedagógico por meio da CA. A aproximação da pedagoga com a CA ocorreu com um trabalho de parceria com o professor-pesquisador Anselmo P. Lima, da área de Letras, com formação no Campo da CA, que ingressou na mesma Universidade em que a pedagoga trabalha, em 2009. Nessa ocasião foi convidado a implantar uma Clínica da Atividade Docente (CADUTFPR) na Instituição (LIMA A; ALTHAUS; RODRIGUES, 2011; LIMA A, 2016a), com a finalidade de contribuir nas ações de promoção de desenvolvimento de práticas docentes. Logo em seguida, ele criou o Grupo de Pesquisa Linguagem, Atividade e Desenvolvimento Humano (GP LAD'Humano), para também estudar as ações desenvolvidas nesse quadro teórico-metodológico.

Com isso, constatou-se uma significativa diferença entre essa abordagem e a anterior, com possibilidades para agir pedagogicamente junto aos professores diante das dificuldades por eles enfrentadas em sala de aula (ALTHAUS, 2013; 2019). Ao invés, de receberem avaliações e recomendações sobre seu trabalho do ponto de vista de outros, nessa abordagem os professores se voluntariam para ter a oportunidade acessar a sua atividade pelo "excedente de visão" (BAKHTIN, 2011), analisarem-na eles mesmos, tomarem consciência e decidirem sobre o que é necessário e passível de mudanças.

Contudo, o pedagogo que se interessa por CA precisa passar por uma formação adequada, dada a complexidade da CA e sua diferença em relação a abordagem de especialista na atividade docente. Como, então, procedeu-se nessa formação?

Desenvolveu-se um dispositivo, no âmbito da CAD e do GP LAD'Humano, em que a formação da pedagoga-interveniente ocorre com base nos preceitos da CA. Apesar de que Clot e colaboradores não tratarem especificamente da formação do interveniente, em várias passagens de sua ampla obra, é possível identificar indícios de como proceder a essa formação e qual o papel deste sujeito nas intervenções (ALTHAUS; BANKSLEITE, 2017; ALTHAUS, 2019). Diante disso, uma orientação que guiou as atividades para a formação de pedagoga-interveniente na CA é a seguinte:

Ele [o interveniente] deve trabalhar com instrumentos, entre os quais os conceitos são tão importantes quanto o coletivo de trabalho, no qual ele pode colocar em discussão suas "maneiras de fazer". Isso supõe experiência, "métier" (CLOT, 2008, p. 68, grifos nossos).

Dessa afirmação destaca-se dois pontos. Um, é que, para realização do trabalho em CA, são indispensáveis "instrumentos", dentre eles os "conceitos".

No quadro do grupo de pesquisa, em que os integrantes têm conhecimentos na perspectiva histórico-cultural, busca-se aprofundar e discutir conceitos de autores como Bakhtin e Vigotski, bem como os relacionados à CA (ALTHAUS, 2019, p. 16).

Outro ponto refere-se à "experiência". Assim sendo, no dispositivo de formação desenvolvido pela CAD e pelo GP LAD'Humano, busca-se realizar os seguintes procedimentos:

inicialmente procede-se à formação de novos intervenientes com a observação, seja através de transcrições e análises de vídeos de autoconfrontações, seja por observação direta de outros mais experientes que atuam na área; posteriormente, os intervenientes em formação 
passam a atuar em situações de autoconfrontações. Essa experiência se realiza sempre em pares de intervenientes, de forma tal que 0 interveniente em formação (IF) realiza autoconfrontações acompanhado de um interlocutor dessa área (ALTHAUS, 2019, p. 16).

Tal experiência em pares tem por inspiração o conceito de Zona de Desenvolvimento Proximal (ZDP) (VIGOTSKI, 2007). Para tanto, segue-se a ideia de que com o apoio de um interveniente mais experiente o Interveniente em Formação (IF) poderá efetuar o que não consegue ainda realizar sozinho e, no futuro, seja capaz de exercer as atividades com autonomia. Desse modo, na experiência de pedagoga-interveniente foi realizada as ações da CA em dupla, sendo o par mais experiente como Interveniente Principal (IP) e o iniciante como Interveniente Auxiliar (IA). Nesse processo, a pedagoga-interveniente vai pouco a pouco se tornando IP e formadora de outra.

É importante destacar que, com base em Vigotski (2007), tem-se a noção de que tal processo não é automático, tão pouco linear, mas é compreendido como um movimento de aprendizagem em determinada área por via da interação entre um menos experiente com outro mais experiente, e desse modo é possível desenvolver maneiras de efetuar certas atividades.

No caso, o exercício da atividade pedagógica por intermédio da CA.

\section{Uma breve apresentação da Clínica da Atividade: Questões CONCEITUAIS E PROCEDIMENTAIS}

A CA, de maneira geral, consiste em uma démarche clínica. Essa, constitui-se por uma postura adotada a partir de um quadro epistemológico que permite elaborar e utilizar dispositivos em situações de trabalho (CLOT, 2010; FAïTA, 2017), "tendo a atividade em movimento como centro de análise e os trabalhadores como protagonistas" (ALTHAUS, 2019, p. 34). Isto é, ter a atividade de ensinoaprendizagem como centro de análise possibilita perceber novas formas de viver na docência através da experiência de trabalho vivida, e ter o professor como protagonista é respeitar a subjetividade e creditar sua capacidade de especialista no que faz (CLOT, 2010; ALTHAUS, 2019).

Para tanto, o pedagogo-interveniente trava um diálogo com os professores a fim de apoiá-los na atividade de perceberem como agem e como podem agir diferente. Portanto, a CA tem como primazia a transformação da ação. Desse modo, empenha-se em provocar e estudar as transformações do poder de agir dos docentes, que se encontram impedidas e/ou a serem desenvolvidas (CLOT, 2010).

Isso pode ser mais bem compreendido considerando os conceitos de "real da atividade" e de "gênero de atividade", elaborados na CA.

O conceito de "real da atividade" foi desenvolvido com base nos conceitos de "trabalho prescrito" e "trabalho realizado" da ergonomia francesa. Sendo que, a "prescrição" diz respeito às regras e regulamentações e o "realizado" é o que de fato é efetuado e pode ser registrado em vídeo. Além disso, a CA é fundamentada na afirmação de que "cada minuto do homem está cheio de possibilidades não realizadas" (VIGOTSKI, 1996, p. 69), por isso considera que entre a prescrição e o realizado existe uma distância, que se refere às diferentes maneiras de se fazer algo (CLOT, 2010).

Ou seja, a experiência vivida e registrada no vídeo - atividade realizada - é apenas uma possibilidade de ação, as outras não realizadas continuam agindo sobre o sujeito. 
Inspirada nessa questão a CA criou um conceito fundamental para tratar das situações de trabalho, o "real da atividade":

\begin{abstract}
o que não se faz, o que se tenta fazer sem ser bem-sucedido - o drama dos fracassos - 0 que se desejaria ou poderia ter feito e o que se pensa ser capaz de fazer noutro lugar. $E$ convém acrescentar - paradoxo frequente - o que se faz para evitar fazer o que deve ser feito; o que deve ser refeito, assim como o que se tinha feito a contragosto (CLOT, 2010, p. 103-104).
\end{abstract}

Com isso, tudo o que não foi realizado apresenta, de algum modo, uma conexão ao vivido, à "atividade realizada" e registrada no vídeo. Compreende-se que o "real da atividade" tem relação com as atividades impedidas, suspensas, contrariadas, que de certa maneira podem afetar o professor e o levar ao adoecimento, se o seu poder de agir não for restaurado (CLOT, 2010; LIMA M; BATISTA, 2016). Contudo, o "real da atividade" pode também ser fonte de saúde, pois é uma via com potencial para a recriação da atividade docente (CLOT, 2010).

Isso é possível a partir da "tomada de consciência" do sujeito por meios indiretos.

Esse processo é realizado por meio de dispositivo metodológico que leve os trabalhadores a refazer a mesma atividade realizada do vídeo por palavras, atraindo o participante para 0 trabalho, e não para a avaliação/julgamento do trabalhador, por meio de certo e errado (ALTHAUS, 2019, p. 44).

O docente ao se analisar em ação no vídeo, além de se voltar para atividade gravada, dirige-se também para seus interlocutores diretos, o interveniente e o seu par na intervenção, e indiretos, por exemplo o gênero do ofício (CLOT, 2010). Desse modo, o professor vê sua atividade pelos olhos dos outros e se sente interpelado a responder de acordo com o "gênero de atividade" (ALTHAUS, 2019, p. 45).

A partir do conceito de "gêneros do discurso [como] tipos relativamente estáveis de enunciados" (BAKHTIN, 2011, p. 262), em CA, criou-se o conceito de "gêneros profissional ou de atividade", que são "tipos relativamente estáveis de atividades socialmente organizadas por um meio profissional" (CLOT, 2010, p. 124). Além disso, Clot afirma que "seria possível dizer que os gêneros do discurso e os gêneros de técnica formam, conjuntamente, o que se pode designar por gêneros de atividade" (2010, p. 123, grifos do autor).

Portanto, pode-se concluir que o gênero técnico, propicia modos de agir e de pensar em certo contexto com o mesmo alcance normativo que os gêneros do discurso ao dispor tipos de enunciados. Assim, ambos, gênero do discurso e de atividade, apresentam dois lados. O lado da estabilidade, que garante uma base de onde partir. E, o lado da relatividade, que é a possibilidade recriação (CLOT, 2010; LIMA A, 2010a).

Os gêneros de atividade, composto por formas de agir, de pensar e de dizer no trabalho são subentendidos e compartilhados pelo coletivo de trabalhadores, pois formam "maneiras de comportar-se, de dirigir a palavra, de encetar uma atividade e de levá-la a termo, de conduzi-la eficazmente a seu objeto [...] formam um repertório de atos convencionados" (CLOT, 2010, p. 123). Ou seja, desenvolve-se uma memória de formas de agir que ficam à disposição do coletivo para serem mobilizadas em atividade de trabalho, como um repertório que pode proteger o trabalhador ante os imprevistos do real, bem como serem recriadas. 
Além disso, destaca-se que, em CA, os gêneros de atividade são compreendidos em quatro dimensões: transpessoal, impessoal, pessoal e interpessoal. As formas/tipos de agir, de pensar e de dizer em comum entre os docentes dizem respeito à dimensão transpessoal; configuram-se como uma senha de conhecimento apenas por quem compõem do gênero (CLOT, 2010). A dimensão impessoal, caracteriza-se pelas questões institucionais em suas prescrições; a dimensão pessoal, condiz com as maneiras que cada professor desenvolve para se apropriar do gênero docente; e a dimensão interpessoal corresponde as relações interlocutivas, uma vez que a atividade tem destinatários, tais como: discentes, sociedade, mundo do trabalho, etc (CLOT, 2008; 2010; OSÓRIO; BARROS; LOUZADA, 2011; LIMA A, 2016a).

O gênero não é acabado, ele está sujeito à estilização, à recriação (CLOT, 2010). Contudo, pode ocorrer nas situações de trabalho que o lado da relatividade fique estagnado e se caia na repetição sem recriação, aí incide a contribuição da CA para recolocar os gêneros em movimento. Essa contribuição se dá por intermédio de meios indiretos, tal como a autoconfrontação ${ }^{9}$, em que:

Cada autoconfrontação faz reviver o gênero de maneira pessoal, oferecendo ao coletivo a possibilidade de um aperfeiçoamento do gênero ou, em todo o caso, a possibilidade de um questionamento capaz de levar à validação de novas variantes (CLOT, 2010, 127).

Desse modo, a CA, em sua démarche, tem como primazia a transformação da ação, isto porque, em CA, assume-se a ideia vigotskiana de que, "é somente em movimento que um corpo mostra o que é" (VIGOTSKI, 2007, p. 68). Esclarece-se que, considera-se, nessa clínica, que "o corpo é o fisiológico desenvolvido em psicológico" (CLOT, 2016, p. 89). Dessa maneira, para a CA:

\begin{abstract}
é apenas através de uma experiência de transformação que a atividade psicológica pode revelar seus segredos. Ora, a única possibilidade de atingir tal objetivo é pelos meios deslocados de um desenvolvimento "provocado". Portanto, o desenvolvimento só pode ser objeto da psicologia se ele é, também, seu método: um método que, para os sujeitos, seja o meio de descobrir suas capacidades ao se avaliarem diante do que eles fazem (CLOT, 2010 , p. 63, grifos do autor).
\end{abstract}

De maneira geral, no quadro metodológico de autoconfrontação:

Trata-se de iniciar um diálogo entre profissionais, dois a dois, por binômio (que serão a seguir multiplicados), em torno de um vídeo da atividade a fim de recuperar controvérsias sobre a atividade em um coletivo e entre "conhecedores" dela. Essas "disputas" têm por finalidade renovar o poder de agir dos envolvidos com o ofício, dando mais autoridade ao fiador coletivo da atividade individual (CLOT, 2011, p. 75).

O dispositivo de autoconfrontação apresenta "várias fases, por sua vez, decompostas em várias etapas" (CLOT, 2010, p. 239). Assim, na CAD em questão, trabalha-se com três fases em cada edição ${ }^{10}$, que são desdobradas em diversas etapas e procedimentos.

\footnotetext{
${ }^{9}$ Em CA há outros métodos, por exemplo a Instrução ao Sósia. Entretanto, nesse trabalho se debruça sobre a autoconfrontação. O leitor que desejar conhecer melhor a instrução ao sósia poderá consultar, por exemplo: Muniz-Oliveira (2009), Clot (2010, p. 201-226) e Batista; Rabelo (2013).

${ }^{10}$ Edição se refere a todas as fases e etapas desenvolvidas com uma dupla de participantes da autoconfrontação.
} 
$\mathrm{Na}$ primeira fase, que antecede as Autoconfrontações, os intervenientes praticam as seguintes ações: realizam uma reunião com o coletivo de professores, organizados por departamentos acadêmicos, para discutir a demanda e constituir uma dupla de profissionais docentes que irá participar de filmagens e Autoconfrontações; coletam autorizações livres e esclarecidas também dos alunos da dupla; efetuam observações da aula desses docentes; fazem uma devolutiva aos professores individualmente sobre as anotações e iniciam o diálogo problematizador com os mesmos (CLOT, 2010, p. 239; ALTHAUS, 2013; 2019; LIMA A; ALTHAUS, 2016).

"Nessa primeira fase dois aspectos destacam-se: 1) o coletivo é o ponto de partida da intervenção; e 2) a observação é instaurada como instrumento de desenvolvimento" (ALTHAUS, 2019, p. 48). Segundo Clot, "a primeira fase, portanto, procura instruir o ponto de vista individual e coletivo" (CLOT, 2010, p. 239). Para tanto, os docentes precisam assumir voluntariamente o instrumento, pois nessa primeira fase o profissional já pode e deve iniciar o processo de se observar e pensar sobre o que seus colegas e o interveniente podem pensar e dizer sobre seus atos, bem como o que ele poderá dizer de si próprio em resposta (LIMA A; ALTHAUS; RODRIGUES, 2011). Ancorado em Vigotski, Clot (2010) afirma que a observação é primeiramente interpsicológica, do pedagogo-interveniente para com o professor $e$, na continuidade, passa a ser intrapsicológica, do sujeito para consigo mesmo. "É assim, e somente assim, que se revela um desenvolvimento subjetivo da experiência vivida" (CLOT, 2010, p. 247).

Na segunda fase, que consiste na realização das Autoconfrontações, os intervenientes exercem as seguintes atividades: filmam uma situação de trabalho de cada docente da dupla; escolhem junto com os professores um trecho para análise por eles mesmos e tendo os intervenientes como coanalista; realizam as sessões de autoconfrontação simples (ACS) com cada docente e de autoconfrontação cruzada (ACC) com trecho de vídeo de cada professor para um analisar a ação do outro na presença desse e discutir com ele (CLOT, 2010, p. 240; CLOT; FAïTA, 2016; LIMA A; ALTHAUS, 2016).

Espera-se que com a filmagem o processo de auto-observação se amplie (LIMA A; ALTHAUS, 2016). Na ACS, cria-se "um contexto em que o sujeito se torna um observador externo de sua própria atividade, em um espaço-tempo laboratorial na presença dos intervenientes" (ALTHAUS, 2019, p. 49-50). Nessa etapa, ocorrem, tipicamente, um movimento psicológico-dialógico manifesto em três estágios: 1) refúgio no coletivo: em geral ocorre no início, quando o docente explica pela primeira vez seus atos registrados no vídeo, apoiando-se, por exemplo, em "nós" e "a gente"; 2) estranhamento: frequentemente na sequência do diálogo, o professor se depara com um "difícil de dizer" momento em que ele não encontra palavras para explicar o que estava fazendo e, então, ampara-se ao individual, ao "eu"; 3) reequilíbrio: situação em que o docente busca e reencontra argumentos que justificam sua ação; nesse ponto a ACS pode ser encerrada porque se torna necessário a introdução de outro interlocutor, um colega do mesmo nível de expertise, portanto outro docente. Isso é possível passando para a ACC (CLOT, 2010, p. 117-154; ALTHAUS, 2013; 2019; CLOT; FAÏTA, 2016;).

$\mathrm{Na}$ ACC, cada professor, na presença de um par - os dois tendo passado pela ACS - e do interveniente, visualiza ao registro de um trecho da ação de seu colega e é orientado pelo interveniente a descrever detalhadamente o que o outro está efetuando na sequência de imagens. "Nessas circunstâncias, cada um observa, na atividade do outro, a própria atividade, reencontrando-a sem a possibilidade de reconhecê-la 
completamente" (CLOT, 2010, p. 241). A partir do que um docente analisa sobre a atividade do outro, ambos são conduzidos pelo interveniente a um diálogo, com base na fundamentação teórica-metodológica da CA e sua ancoragem (CLOT, 2010; CLOT; FAÏTA, 2016).

Nesse momento, podem ocorrer dois estágios: 1) reinterrogação de si: quando cada um dos docentes observa sua atividade na atividade do outro e pode a repensar acessando o ponto de vista do outro; 2) controvérsia: os pontos de vistas geralmente são diferentes e frequentemente se modificam no fluir da análise, passando para um outro ponto de vista (CLOT, 2010, p. 117-154; ALTHAUS, 2013; CLOT; FAIITA, 2016;). "Ao se confrontar com a opinião e os questionamentos de seu colega, quase sempre há controvérsia: o trabalhador se obriga a buscar novas referências [...] Isto é, a ACC o coloca em uma nova ZDP" (ALTHAUS, 2019, p. 50-51).

Nesse processo, o diálogo é como uma mola que impulsiona para o desencadeamento das transformações da atividade docente. Ancorado na afirmação de Bakhtin (2011), de que a última palavra nunca é dita, Clot (2011) assinala que a atividade também não é acabada. Assim sendo, o "real da atividade" é colocado em discussão a partir da "atividade realizada" e gravada no vídeo, de modo que as controvérsias e análises possam levar a outra maneira de pensar e agir.

Isto ocorre por via de um movimento psicológico-dialógico tríade que convoca diferentes destinatários: os imediatos, tais como o interveniente e o colega de trabalho com quem forma dupla; o sobredestinatário, o ofício de maneira mais ampla; e, subdestinatário, que corresponde a um contato consigo mesmo (CLOT, 2010). Nesse diálogo, ocorrem discordâncias consigo mesmo e com os outros, que possibilitam mudanças.

$\mathrm{Na}$ terceira fase, após as Autoconfrontações, é o momento de retorno ao coletivo para compartilhar com eles as novas proposições de modos de agir no trabalho e tomada de decisões. Para isso, é: elaborado um videodocumentário pelo interveniente em conjunto com os professores autoconfrontados; realizada uma reunião com o coletivo de docentes para apresentação e análise em conjunto do material resultante das Autoconfrontações, com a finalidade de que as alterações necessárias para implementar melhorias no trabalho sejam assumidas pelo grupo se assim decidirem (CLOT, 2010, p. 241; ALTHAUS, 2013; 2019; CLOT; FAIITA, 2016; LIMA A, ALTHAUS, 2016).

Dessa maneira, busca-se também contribuir para a (re)organização dos coletivos de trabalho, pois "existe, entre a organização do trabalho e o próprio sujeito, um trabalho de reorganização da tarefa pelos coletivos profissionais, uma recriação" (CLOT, 2010, p. 119), com a clareza de que a última palavra nunca é dita (BAKHTIN, 2011).

\section{UMA AMOSTRA DE INTERVENÇÃO PEDAGÓGICA COM CLÍNICA DA ATIVIDADE E DE ANÁLISE}

Segue abaixo uma amostra de intervenção pedagógica em CA. Trata-se de uma ACS, realizada com o Professor Cândido (PC) de Ciências Contábeis, aqui denominado ficticiamente. A pedagoga-interveniente atua como IP e na formação de outra, a IA. A sequência apresentada abaixo ocorre após o PC se visualizar em ação docente e revelar 
um problema de ter cinco aulas seguidas de Auditoria Contábil, que leva os alunos de graduação a diminuir a atenção e a participação ${ }^{11}$.

Quadro 1: Sequência da segunda participação da IF como $\mathrm{IA}^{12}$

01 PC: o Coordenador fez o horário o ano passado para conseguir me colocar na segunda e terça que é o: os dias que eu:: podia vim... ele colocou cinco aulas na ((riso)) na segunda

02 IP: e está dando certo isso?

03 PC: não:: eu não vejo como positivo... acho melhor pôr em dois dias... já s:olicitei ao Coordenador para ano que vem

04 IP: aí ano que vem vocês já:: estão se PLANEJANDO para trabalhar:: cinco aulas dividido em dois dias e não em

05 PC:

sim

06 IP:

[

em uma noite só... é da mesma disciplina essas aulas?

07 PC: sim

$08 \mathrm{IP}$ : hum::

09 IA: é:: tem alguma estratégia que você utiliza para MANTER a atenção dos alunos CINCO aulas seguidas? por que realmente é MUITO cansativo né? independente da matéria

10 PC:

tempo né?

é a questão do

$11 \mathrm{IA:} \quad$ [

então tem alguma estratégia? algum::

$12 \mathrm{PC}$

\section{[}

ah estratégia EXTRA não... por ser cinco aulas ou três não tem uma estratégia assim... a estratégia é a mesma:: né? a estratégia é a mesma:: a estratégia é a mesma como se fosse três ou cinco:: enfim

13 IP: será que não ajudaria: ter uma estratégia? pensando quando é um período LONGO assim que você falou que não deu certo... né? já viu que:: não dá para continuar assim... talvez se tiver se 14 PC:

15 IP:

vejo que assim que não está preju/

não ser tão pesa:do:: a dar ce:rto::

INTRODUZIR alguma estratégia diferente isso ajudaria a a a::

16 PC: não a gente procura:: tal alguma coisa assim dar algu::ns exercício:::

17 IP:

$18 \mathrm{PC}$ :

uhum e além dos exercícios?

(bota no

meio alguns) exercícios e tal... né? aí claro entre a::-- não é conteúdo né? -- eu procuro sempre...

\footnotetext{
11 Dados eram pré-existentes à realização da pesquisa.

12 No quadro há três colunas. Na primeira está identificado o número do turno de fala analisado, e serão marcados em sequência. A segunda coluna corresponde ao falante que está se pronunciando. E na terceira encontram-se os enunciados proferidos e transcritos. As transcrições foram realizadas por Alana Destri e revisadas por Dalvane Althaus. O material completo se encontra com a pedagoga-pesquisadora e com 0 GP LAD'Humano. A transcrição segue as normas do projeto NURC, com os seguintes símbolos e significados: "( )", palavras não compreendidas; "(x)", hipótese do que se ouve; "”, truncamentos na fala; "XXX”, entonação na fala; “.”, prolongamento; “-”, silabação; “...”, pausa; “((x))", comentários do transcritor; "- x --", digressão na sequência temática; " [", sobreposição de vozes; "', citações literais (PRETI, 2001).
} 
é:: ou conto uma piadinha no meio ou traz um vídeo meio engraçado:: né? eu tenho sempre uns videozinhos engraçados aí

Fonte: Banco de dados do GP LAD'Humano, produzidos em 2013 e disponíveis em Althaus (2019, p. 75).

Nesse excerto, PC destaca a situação de ter cinco aulas seguidas e, apesar de ser um pedido seu atendido pelo Coordenador, solta um riso que parece nervoso (Turno - T. 01). Isso revela que pode haver algum problema com esse horário. A IP pergunta se está dando certo e PC responde que não vê como positivo, e por isso já solicitou uma alteração para as próximas turmas.

Diante dessa dificuldade revelada por PC, IA, interveniente em formação, lança-se por alternância de turno com IP para questionar se o professor teria alguma estratégia para manter a atenção dos alunos (T. 09). Esse questionamento traz a ideia de que é necessário ter estratégias em sala de aula, a fim de evitar a monotonia. As palavras em caixa alta, "MANTER", "CINCO" e "MUITO", marcam um discurso mais impulsivo, com entonações fortes. Embora, possa ser uma concordância com o posicionamento do PC no turno 3, quando diz que "não vê como positivo" a situação, pode ser entendida também como uma "escorregada" para a posição de especialista na atividade docente, que sugere algo. Entretanto, a interveniente logo modera seu posicionamento fazendo uma correção em seu discurso, dizendo que é cansativo "independente da matéria". Além disso, tal complemento, invoca o "sobredestinatário" (BAKHTIN, 2011; VOLÓCHINOV, 2017), pois para qualquer professor poderia ser cansativo trabalhar cinco aulas seguidas de auditoria contábil, com a mesma turma.

PC demonstra se sentir afetado com a pergunta de IA, pois ele se sobrepõe a voz dela para justificar que "é a questão do tempo" e não de estratégia de aula. Porém, a IA retoma a palavra e questiona novamente de modo mais direto e diz "então tem alguma estratégia?" (T. 11). Outra vez, o professor interrompe a fala da interveniente e responde de maneira titubeante que não tem, ou não lembra de ter formas diferentes para trabalhar.

Nesse ponto, a interveniente em formação não dá continuidade ao desenvolvimento da questão e coube a IP prosseguir, que, então, retoma a questão sobre estratégias relacionando com a ideia trazida anteriormente pelo próprio professor de que não estava sendo positivo do modo como vinha sendo feito: "será que não ajudaria: ter uma estratégia? pensando quando é um período LONGO assim que você falou que não deu certo... né? já viu que:: não dá para continuar assim" (T. 13). Essa pergunta, comparada com as outras realizadas pela IP, mostra um juízo de valor maior ao questionar na condicional. Isto é, nessa relação interlocutiva, com a intervenção de IA, IP passa de um tom menos valorativo para mais. O PC ensaia a resposta com a ideia de que não haveria "prejuízo", mas não concluiu a palavra (T. 14). Isso indica que possivelmente ele está "reformulando" (ARIATI, 2018) seu pensamento.

Diante da dificuldade de o professor concluir que não haveria prejuízo, a IP insiste na questão sobre a possibilidade de estratégias extras. PC, então, efetua uma reformulação respaldado no coletivo dizendo que "a gente procura" colocar alguns exercícios (T. 16). Assim, diante de novos questionamentos o professor pode repensar sobre o modo como vinha realizando sua atividade e se recorda que lança mão, também, de "piadinhas" e "vídeozinhos engraçados", mas que estes não são conteúdos (T. 18).

A mudança de posicionamento do professor, que, inicialmente, afirma não ter estratégias extras, e, na sequência, consegue as identificar no seu trabalho realizado e explicar algumas possibilidades, ocorre por meio do diálogo com as intervenientes. Isso pode ser 
mais bem compreendido a partir de Vigotski (1998), que afirma que é através do pensamento que as palavras passam a existir. Portanto, ao dialogar sobre sua atividade com as intervenientes o professor elucida para ele mesmo sobre o seu modo de agir e 0 valor que isso tem do seu ponto de vista. As suas estratégias verbalizadas no diminutivo indicam que o professor as considera de pouco valor, possivelmente não se sente realizado no trabalho.

Em suma, esse excerto inicia com o professor apresentando uma dificuldade, que considera encargo de o coordenador de curso resolver e com a IP fazendo perguntas de modo mais imparcial. Porém, a entrada da interveniente em formação, IA, de uma maneira mais impulsiva dando a entender que é atribuição do professor ter estratégias extras em aula leva ele a demonstrar um afetamento, marcado pela dinâmica do diálogo com interrupções, pausas, alongamento das vogais, truncamento e repetição de palavras. Isto é, desloca-o da zona de conforto. A continuidade da interação com a IP, que adere ao tom mais valorativo, conduziu-o a perceber mais claramente como tem desenvolvido sua atividade e a revelar um descontentamento com suas estratégias descritas no diminutivo.

Poder-se-ia analisar se, em relação à docência, PC estaria desviando do gênero profissional pelo fato de os "videozinho e as piadinhas" não terem relação com o conteúdo, ou se estaria buscando manter a atenção dos alunos, e sua própria, ou se seria uma estratégia utilizada já por outros professores em outros contextos. Entretanto, não é o foco deste texto.

Ressalta-se que, o juízo de valor colocado nas questões direcionados ao professor é embasado em sua fala anterior. E, apesar, de o professor ter conseguido perceber o que faz em sala e o valor que sua ação tem para ele mesmo, não houve indícios de que na sequência tenha introduzido mudanças na atividade. Porém, desligou-se da carreira docente. Muito embora, não seja possível afirmar com certeza que tenha sido um resultado clínico, um estudo que analisou o material dialógico produzido com PC, aponta que: "pode-se considerar que ela [a intervenção] tenha contribuído para que ele refletisse mais sobre sua atividade profissional, que olhasse para sua saúde e conseguisse encontrar uma nova forma de agir, de buscar saúde" (SARTORI, 2017, p. 90). Utilizar estratégias de ensino de pouco valor é motivo de desrealização na docência, por conseguinte pode afetar a saúde do professor.

\section{CONSIDERAÇÕES FINAIS}

Este texto, tratou do trabalho do pedagogo pela via da CA, para tanto apresentou-se uma experiência estudada mais amplamente em uma tese sobre os aspectos da formação e do papel do interveniente (ALTHAUS, 2019). O interesse pelo tema teve origem a partir da experiência de uma pedagoga-pesquisadora que se tornou pedagoga-interveniente em CA.

Desse modo, desenvolveu-se cinco tópicos. No primeiro, resgatou-se brevemente as primeiras experiências como pedagoga em colégios estaduais, na modalidade de educação básica, evidenciando-se a sobrecarga de tarefas na atividade de coordenador pedagógico. No segundo, relatou-se sobre o ingresso da pedagoga no ensino superior e a posição de especialista na atividade dos professores, bem como a dificuldade para atuar na formação docente continuada. No terceiro, apresentou-se uma possibilidade de recriação da atividade do pedagogo por meio da $\mathrm{CA}$, que desloca o trabalho do 
pedagogo de especialista na atividade docente para o organizador do ambiente em que o professor é o protagonista do desenvolvimento de suas práticas, e os procedimentos de formação para se tornar interveniente. No quarto, descreve-se a CA e alguns conceitos imprescindíveis nesse meio, tais como: "real da atividade", "gênero de atividade" e "autoconfrontação". No quinto, mostrou-se um excerto de uma transcrição de autoconfrontação simples com um professor de Ciências Contábeis, e uma análise sucinta da relação interlocutiva e os desdobramentos para o professor e para as intervenientes.

Ressalta-se que, o exercício do trabalho de coordenação pedagógica na posição de especialista na atividade docente é dominante nesse gênero. Foi aprendido por esta pesquisadora na formação inicial no curso de Pedagogia e na prática desta atividade, inicialmente, na educação básica e, na sequência, no ensino superior. Contudo, foram muitas as dificuldades e tensões para exercer o trabalho nessa posição de expert, que julga e faz recomendações de "boas práticas" ao trabalho do outro (ALTHAUS, 2013; 2019).

No percurso profissional a pedagoga-pesquisadora teve a possibilidade de se aproximar da CA e com isso a oportunidade de efetuar mudanças em sua atuação pedagógica (ALTHAUS, 2013). Pois, diferentemente da posição de especialista na atividade do outro a CA visa a provocar transformações em situações de trabalho tendo o profissional como protagonista (CLOT, 2010). Isso porque, de modo geral, o gênero é como uma senha "conhecida apenas pelos agentes da atividade e formam repertórios de modos de agir, que servem para os trabalhadores saberem o que devem/podem ou não fazer ou como agir diante de imprevistos e impedimentos" (ALTHAUS, 2019, p. 121).

Desse modo, a CA contribui para que os docentes (re)descubram outras possibilidades de agir diferentes das efetuadas no momento da ação por meio de métodos indiretos, tal como a autoconfrontação. Nesta, os professores são levados a se observarem e se veem conduzindo a aula para que então eles mesmos possam perceber como fazem e como podem fazer diferente, isto é, eles têm a oportunidade de ampliar sua "consciência profissional" (LIMA A, 2016c). Na amostra apresentada e discutida, observou-se resultados clínicos de afetamento do professor, que o levou a pensar e a repensar sua prática.

Para tanto, o pedagogo que deseja atuar em CA precisa passar por um processo de formação, assim como a referida pedagoga o fez. Tal formação envolve estudar e praticar CA, com o apoio de grupo de pesquisa e de um par mais experiente (VIGOTSKI, 2007; ALTHAUS, 2019).

Desse modo, nas sessões de autoconfrontação se tem uma interveniente mais experiente, denominada de interveniente principal (IP), e uma interveniente em formação auxiliando (interveniente auxiliar - IA) na intervenção enquanto acompanha e aprende a atuar em CA. Constatou-se no estudo da tese, e na amostra aqui apresentada, que a interveniente em formação se lança para intervir apoiada em seu par mais experiente, nesse caso, por alternância de turno e deixando o desenvolvimento do assunto para a IP continuar.

Embora, a CA tenha uma orientação clara para não se colocar como especialista na atividade do outro, na prática isso é difícil de ser implementado. $O$ excerto analisado mostra as intervenientes oscilando no juízo de valor - ora para menos, ora para mais das questões lançadas ao professor. Isso pode ser compreendido tendo em vista o conceito de "atividade reguladora" que: "corresponde a um processo de oscilação do 
sujeito falante entre opostos contraditórios implicados em sua ação/atividade" (LIMA A, 2017, p. 127). Segundo o autor, essa regulação é identificada com maior grau nas situações de comunicação em que o sujeito não domina completamente o gênero em uso, fenômeno esse observável na IF, porém mesmo em sujeitos que com mais experiência em determinado gênero a oscilação não cessa totalmente porque a língua é viva e a atividade também. Nesse caso, percebeu-se, que a IA inicia com uma entonação mais valorativa e vai buscando "regular" (LIMA A, 2010b) seus enunciados. Contudo, a IP, que mesmo sendo mais experiente, também, "regula" sua posição de menos valorativa para mais. Isso remete a ideia de que o interveniente ter um par "interlocutor", isto é outro interveniente durante a sessão, ajuda-o a organizar seu pensamento e a ajustar seu posicionamento de interveniente durante a autoconfrontação (VIGOTSKI, 2007; BAKHTIN, 2011).

Diante disso, considera-se que a CA, além de contribuir para o desenvolvimento das práticas docentes, contribui também para a recriação da atividade do pedagogo, tal qual desta autora e de outros ${ }^{13,}$ que buscam na CA ou apoio para realização do trabalho, ou para pesquisa, ou mesmo inspiração.

\section{REFERÊNCIAS}

ALTHAUS, Dalvane. Complexidade e Relevância de um Gesto Profissional Docente Aparentemente Simples. 2013. 200 f. Dissertação (Mestrado em Desenvolvimento Regional) - Programa de PósGraduação em Desenvolvimento Regional, Universidade Tecnológica Federal do Paraná. Pato Branco, 2013. Disponível

http://repositorio.utfpr.edu.br/jspui/bitstream/1/755/1/PB_PPGDR_M_Althaus\%2c\%20Dalvane_2013.pdf

ALTHAUS, Dalvane. Aspectos da formação e do papel do interveniente na Clínica da Atividade: um estudo de caso em situação de autoconfrontação. 1 recurso online (163р.). Tese (doutorado) - Universidade Estadual de Campinas, Faculdade de Educação, Campinas, SP, 2019. Disponível em < http://repositorio.unicamp.br/jspui/bitstream/REPOSIP/335042/1/Althaus_Dalvane_D.pdf>Acesso em 31 de jan de 2020.

ALTHAUS, Dalvane; BANKS-LEITE, Luci. O interveniente em clínica da atividade: considerações sobre seu papel e sua formação. Horizontes, V. 35, n. 3, 2017, p. 121-132.ANASTASIOU, Léa. Estratégias e técnicas de ensino. In: Semana de Planejamento de Ensino do 1ํ Semestre de 2011. Palestra. Pato Branco, UTFPR, 2011.

ANJOS, Daniela Dias dos. A profissão docente em questão: gênero de atividade, gênero de discurso e habitus. 2013. 225 p. Tese (doutorado) - Universidade Estadual de Campinas, Faculdade de Educação, Campinas, SP, 2013.

ARIATI, Solange. Autoparáfrase em situação de autoconfrontação: pensando e (re)pensando o ensino de matemática no ensino superior. 2018. Dissertação (Mestrado em Letras) - Programa de Pós-Graduação em Letras na Universidade Tecnológica Federal do Paraná. Pato Branco, 2018.

BAKHTIN, Mikhail (Volochínov). Estética da criação verbal. Trad. Paulo Bezerra. 4.ed. São Paulo: Martins Fontes, 2011.

BARRICELLI, Ermelinda. Transformações e conflitos no processo de elaboração, de difusão e de utilização de instruções oficiais de educação infantil: um estudo genealógico. 2012. 222 f. Tese (Doutorado em Linguística) - Pontifícia Universidade Católica de São Paulo, São Paulo, 2012.

\footnotetext{
13 Pode-se citar outros pedagogos, como Barricelli (2012), Anjos (2013), Brito (2017), Guimarães (2017), Mariutti (2017), Ramos (2017), Rodrigues (2017), Santos (2018), que têm buscado na CA pressupostos para atuação prática e/ou de pesquisa.
} 
BATISTA, MATILDE A.; RABELO, LAÍS. Imagine que eu sou seu sósia. Aspectos técnicos de um método em clínica da atividade. Cadernos De Psicologia Social Do Trabalho, 16(1), 1-8, 2013.

BRITO, Ana Paula Souza. Orientador/a pedagógico/a: o que você faz na escola?: uma análise dos diferentes estilos e do gênero de atividade. 2017. 1 recurso online (202 p.). Tese (doutorado) - Universidade Estadual de Campinas, Faculdade de Educação, Campinas, SP, 2017.

CLOT, Yves. A função psicológica do trabalho. Trad. Adail Sobral. Petrópolis: Vozes, 2006.

CLOT, Yves. De l'analyse des pratiques au développement des métiers, Éducation et didactique [En ligne], vol 1 - $n^{\circ} 1$, avril 2007. Disponível em: $h$ ttp://journals.openedition.org/educationdidactique/106. Acesso em 08 mai 2018.

CLOT, Yves. La recherche fondamentale de terrain: une troisième voie. Education Permanente, vol 4, n. 177, 2008, p. 67-79.

CLOT, Yves. Trabalho e poder de agir. Trad. Guilherme João de Freitas Teixeira e Marlene Machado Zica Vianna. Belo Horizonte: Fabrefactum, 2010.

CLOT, Yves Clínica do Trabalho e clínica da atividade. In: BENDASSOLLI, Pedro F.; SOBOLL, Lis A. (orgs.). Clínicas do Trabalho: novas perspectivas para compreensão do trabalho na atualidade. São Paulo: Atlas, 2011, p. 71-83.

CLOT, Yves. A interfuncionalidade dos afetos, das emoções e dos sentimentos: o poder de ser afetado e o poder de agir. Trad. Luci Banks-Leite. In: BANKS-LEITE, Luci; SMOLKA, Ana L. e ANJOS, Daniela D. (org.) Diálogos na perspectiva histórico-cultural: interlocuções com a clínica da atividade. Campinas: Mercado das Letras, 2016, p. 87-95.

CLOT, Yves. Clínica da Atividade. Tradução Suélen Maria Rocha e Emily Carolina da Silva. Horizontes. v. 35, n. 3, p. 18-22, set/dez. 2017. Disponível em http://revistahorizontes.usf.edu.br/horizontes/article/view/526/239. Acesso em 16 ago. 2018.

CLOT, Yves; FAÏTA, Daniel. Gêneros e estilos em análise do trabalho: conceitos e métodos. Trad. Rozânia Moraes; Aline L. G. Farias. Trabalho \& Educação, Belo Horizonte, v.25, n.2, p. 33-60, mai-ago de 2016.

CUNHA, Maria Isabel da. O bom professor e sua prática. Campinas: Papirus, 6ª reimpr., 1997.

CRUZ, Giseli B. da. Curso de pedagogia no Brasil: história e formação com pedagogos primordiais. Rio de Janeiro: Wak editora, 2011.

FAÏTA, Daniel. La conduite du TGV: exercices de style. Cahier Langage \& Travail, França, N. 8, 1997.

FAÏTA, Daniel. Entrevista: De l'enseignement de la linguistique générale à l'analyse du travail enseignant. Entrevistadoras: Daniela Anjos e Ermelinda Barricelli. Horizontes, V. 35, n. 3, 2017, p. 8-17.

FERREIRA, Naura S. C. Os impactos da contemporaneidade na formação humana e profissional. In: Semana de Planejamento de Ensino do 1ํ Semestre de 2009. Palestra. Pato Branco, UTFPR, 2009.

FERRI, Alceno A. Compromisso Social do professor universitário. In: Semana de Planejamento de Ensino do 1을 Semestre de. Palestra. Pato Branco, UTFPR, 2007.

GASPARIN, João L. Uma didática para pedagogia histórico-crítica. 3. ed. rev. Campinas: Autores Associados, 2005.

GATTI, Bernardete A. Formação do professor pesquisador para o ensino superior: desafios. In. BARBOSA, Raquel Lazzari Leite (Org.) Trajetórias e perspectivas da formação de educadores. São Paulo: Editora UNESP, 2004, v. 01, p. 433-442.

GIL, Antônio C. Metodologia do ensino superior. 4. Ed. São Paulo: Atlas, 2005.

GUIMARÃES, Núbia Silvia. O trabalho com literatura e o desenvolvimento cultural de adultos e crianças na educação infantil. 2017. 1 recurso online (260 p.). Tese (doutorado) - Universidade Estadual de Campinas, Faculdade de Educação, Campinas, SP, 2017.

LEITE, José Carlos C. (org.). UTFPR: uma história de 100 anos. Curitiba: Ed. UTFPR, 2010.

LEITE, Sérgio. A. S.; BERNARDO, F. O.; MOREIRA, A. L. A. Espaço de formação pedagógica para o docente no ensino superior: entrevista com Sérgio Leite. Revista Docência do Ensino Superior, v. 7, 2017, p. 211-221. 
LIBANEO, José C. Didática. 24. reimpr. São Paulo: Cortez, 2005.

LIMA, Anselmo. P. (Re)pensando o Problema dos Gêneros do Discurso por meio de uma relação entre Bakhtin e Vigotsky. Bakhtiniana. São Paulo, V. 1, N. 3, p. 113-126, 1ํsem., 2010a.

LIMA, Anselmo. P. Visitas Técnicas: interação escola-empresa. Curitiba: CRV, 2010b.

LIMA, Anselmo. P. Clínica da Atividade Docente. Blog. 2016a. Disponível em: http://formacaoesaudedoprofessor.com/2016/03/28/clinica-da-atividade-docente-uma-proposta-deformacao-continuada-e-de-promocao-da-saude-do-professor-no-trabalho Acesso em 07 de fev de 2017.

LIMA, Anselmo. P. Como ocorrem nas escolas as tradicionais iniciativas de formação docente continuada e qual é o resultado. Blog. 2016b. Disponível em: https:/formacaoesaudedoprofessor.com/2016/02/01/comoocorrem-nas-instituicoes-de-ensino-as-tradicionais-iniciativas-de-formacao-docente-continuada-e-qual-e-oresultado/. Acesso em 25 de jun de 2018.

LIMA, Anselmo. P. Consciência Profissional: o professor diante do espelho. Blog. 2016c. Disponível em: http://formacaoesaudedoprofessor.com/2016/03/07/consciencia-profissional-no-trabalho-docente-em-salade-aula-implicacoes-para-a-saude-do-professor/ Acesso em 17 de jan de 2020.

LIMA, Anselmo. P. Discurso e atividade reguladora. In: Maria da Glória di Fanti; Helena Nagamine Brandão. (Org.). Discurso: tessituras de linguagem e trabalho. São Paulo: Cortez, 2017, p. 127-146.

LIMA, Anselmo. P; ALTHAUS, Dalvane. Formação docente continuada, desenvolvimento de práticas pedagógicas em sala de aula e promoção da saúde do professor: relações necessárias. Revista Brasileira de Estudos Pedagógicos. V. 97, n. 245, jan./abr. 2016.

LIMA, Anselmo. P; ALTHAUS, Dalvane; RODRIGUES, Claudinéia L. S. (). Formação Docente Continuada e Desenvolvimento do Protagonismo Discente na Universidade: faces de uma mesma moeda. Revista Synergismus Scyentifica, Pato Branco V6 (1), 2011.

LIMA, Maria Elizabeth A.; BATISTA, Matilde Agero. O papel do expertlespecialista versus Clínico/intervenant em clínica da atividade - afinal quem analisa a atividade de trabalho? In: BANKS-LEITE, Luci; SMOLKA, Ana L. e ANJOS, Daniela D. (org.) Diálogos na perspectiva histórico-cultural: interlocuções com a clínica da atividade. Campinas: Mercado das Letras, 2016, p. 113-129.

MARIUTTI, Mariana Martins Volpato. A dimensão pedagógica no métier da diretora. 2017. 1 recurso online (190 p.). Dissertação (mestrado) - Universidade Estadual de Campinas, Faculdade de Educação, Campinas, SP, 2017.

MUNIZ-OLIVEIRA, Siderlene. A instrução ao sósia e a formação docente. In: 17ํㅡㄹ Congresso de Leitura do Brasil, 2009, Campinas. 17을 Congresso de Leitura do Brasil, 2009.

NUNES, Cesar. A educação e os desafios contemporâneos. In: Semana de Planejamento de Ensino do 1ำ Semestre de 2008. Palestra. Pato Branco, UTFPR, 2008.

OSÓRIO, Claudia; BARROS, Maria E. de B.; LOUZADA, Ana P. F. Clínica da Atividade: dos conceitos às apropriações no Brasil. In: BENDASSOLLI, Pedro F.; SOBOLL, Lis A. (orgs.). Clínicas do Trabalho: novas perspectivas para compreensão do trabalho na atualidade. São Paulo: Atlas, 2011, p. 188-207.

PARANÁ. Lei complementar no.103/2004. 2004. Disponível em https://www.legislacao.pr.gov.br/legislacao/pesquisarAto.do?action=exibir\&codAto=7470\&codltemAto=63745. Acesso em 1 de jun. de 2019.

PIMENTA, Selma. G.; ANASTASIOU, Lea. G. C. Docência no ensino superior. 4. ed. São Paulo: Cortez, 2010.

PRETI, Dino. (org.). Análise de textos orais. 5.ed. São Paulo: Humanitas, 2001.

RAMOS, Elizangela K. Desenvolvimento de práticas pedagógicas por meio da implementação de uma clínica da atividade docente no Colégio Estadual Carlos Gomes. 2017. 99 f. Dissertação (Mestrado em Desenvolvimento Regional) - Programa de Pós-Graduação em Desenvolvimento Regional, Universidade Tecnológica Federal do Paraná. Pato Branco, 2017.

RAMOS, Elizangela K. Desenvolvimento de práticas pedagógicas por meio da implementação de uma clínica da atividade docente no Colégio Estadual Carlos Gomes. 2017. 99 f. Dissertação (Mestrado em Desenvolvimento Regional) - Programa de Pós-Graduação em Desenvolvimento Regional, Universidade Tecnológica Federal do Paraná. Pato Branco, 2017. 
RANGEL, Mary. Supervisão: do sonho à ação: uma prática em transformação. In: FERREIRA, Naura S. C. (org.) Supervisão Educacional: para uma escola de qualidade da formação à ação. 2. Ed. São Paulo: Cortez, 2000, p. 69-96.

RANGEL, Mary. Considerações sobre o papel do supervisor, como especialista em educação, na América Latina. In: SILVA JUNIOR, Celestino A. da; RANGEL, Mary (orgs.). Nove olhares sobre a supervisão. 14. Ed. Campinas: Papirus, 2008, p. 147-161.

RODRIGUES, Sirlei. A semana pedagógica como formação continuada de professores: um olhar a partir do método de instrução ao sósia. 2017. 126 f. Dissertação (Mestrado em Letras) - Programa de PósGraduação em Letras, Universidade Tecnológica Federal do Paraná. Pato Branco, 2017.

SANTOS, Clarice D. da S. Práticas pedagógicas: um olhar a partir da clínica da atividade. 2018. Dissertação (Mestrado em Desenvolvimento Regional) - Programa de Pós-Graduação em Desenvolvimento Regional, Universidade Tecnológica Federal do Paraná. Pato Branco, 2018.

SARTORI, Danieli G. Construção de sentidos da sobrecarga no trabalho de professores do magistério superior: saúde via atividade liguageira. 2017. Dissertação (Mestrado em Letras) - Programa de PósGraduação em Letras, Universidade Tecnológica Federal do Paraná. Pato Branco, 2017.

SAVIANI, Dermeval. A supervisão Educacional em perspectiva histórica: da função à profissão pela mediação da ideia. In: FERREIRA, Naura S. C. (org.) Supervisão Educacional: para uma escola de qualidade da formação à ação. 2. Ed. São Paulo: Cortez, 2000, p. 13-38.

SILVA JUNIOR, Celestino A. Supervisão, currículo e Avaliação. In: FERREIRA, Naura S. C. (org.) Supervisão Educacional: para uma escola de qualidade da formação à ação. 2. Ed. São Paulo: Cortez, 2000, p. 223-233.

SILVA JUNIOR, Celestino A.. Organização do trabalho na escola pública: o pedagógico e o administrativo na ação supervisora. In: Campinas: Papirus, 2008, p. 91-109.

VIGOTSKI, Lev. S. Teoria e método em psicologia. Trad. Cláudia Berliner. São Paulo: Martins Fontes, 1996.

VIGOTSKI, Lev. S. Pensamento e linguagem. Trad. Jefferson Luiz Camargo. 2.ed. São Paulo: Martins Fontes, 1998.

VIGOTSKI, Lev. S. A formação social da mente. Trad. José Cipolla Neto et al. 7.ed. São Paulo: Martins Fontes, 2007.

VOLOCHINOV, Valentin. Marxismo e Filosofia da Linguagem: problemas fundamentais do método sociológico na ciência da linguagem. Trad. Sheila Grillo e Ekaterina V. Américo. São Paulo: Editora 34, 2017.

WERNECK, Hamilton. Avaliação. In: Semana de Planejamento de Ensino do º Semestre de 2008. Palestra. Pato Branco, UTFPR, 2008.

ZABALZA, Miguel A. O Ensino Universitário: seu cenário e seus protagonistas. Trad. Ernani Rosa. Porto Alegre: Artmed, 2004.

Data da submissão: 20/04/2020

Data da aprovação: 18/05/2020 